Steuerberater-Jahrbuch 2020/2021 



\title{
Steuerberater-Jahrbuch 2020/2021
}

\author{
zugleich Bericht \\ über den 72. Fachkongress der Steuerberater \\ Köln, 3. und 4. November 2020
}

Herausgegeben

im Auftrag des Fachinstituts der Steuerberater von

Prof. Dr. Thomas Rödder

Steuerberater, Wirtschaftsprüfer
Prof. Dr. Marcel Krumm

Universitätsprofessor im zweiten Hauptamt Richter am Finanzgericht

\section{ottoschmidt}




\section{Zitierempfehlung:}

Verfasser, StbJb. 2020/2021, Seite ...

Bibliografische Information

der Deutschen Nationalbibliothek

Die Deutsche Nationalbibliothek verzeichnet diese

Publikation in der Deutschen Nationalbibliografie; detaillierte bibliografische Daten sind im Internet über http://dnb.d-nb.de abrufbar.

Verlag Dr. Otto Schmidt KG

Gustav-Heinemann-Ufer 58, 50968 Köln

Tel. 02 21/9 37 38-01, Fax 02 21/9 37 38-943

info@otto-schmidt.de

www.otto-schmidt.de

ISSN 0081-5519

ISBN 978-3-504-62667-9

(C2021 by Verlag Dr. Otto Schmidt KG, Köln

Das Werk einschließlich aller seiner Teile ist urheberrechtlich geschützt. Jede Verwertung, die nicht ausdrücklich vom Urheberrechtsgesetz zugelassen ist, bedarf der vorherigen Zustimmung des Verlages. Das gilt insbesondere für Vervielfältigungen, Bearbeitungen, Übersetzungen, Mikroverfilmungen und die Einspeicherung und Verarbeitung in elektronischen Systemen.

Das verwendete Papier ist aus chlorfrei gebleichten Rohstoffen hergestellt, holz- und säurefrei, alterungsbeständig und umweltfreundlich.

Satz: WMTP, Birkenau

Druck und Verarbeitung: Kösel, Krugzell

Printed in Germany 